\title{
Mass Media Sports Information on Activity of Sports of University Students
}

\author{
Yanping Jiang \\ Xi’an Medical University, Xi`an, China \\ yanping@163.com
}

Keywords: Mass communication, Sports information, Mass media

\begin{abstract}
The mass media is a new social power; modern college students are covered and impacted more and more widely. It can not be ignored that the mass media has become an important channel to influence college sports life. In this paper, we analyze the influence of mass media sport on the college student and give some advice to them.
\end{abstract}

\section{Introduction}

In modern society, sport is inseparable from public broadcast media; the mass media is also inseparable from sport. The more developed societies, the relationship between sport and the mass media more closely. We can say that the presence of the media is the attitude of an important space for contemporary sports. Thinking about the relationship between the mass media and sport has become unavoidable in today's sports world [1-3]. However, modern media information passes numerously and unorganized, all-inclusively, resulting in many students have accepted the media sports information but lost the ability to identify, they can not make the right choices and judgments, thus cultivate the media literacy is particularly important [4].

Physical and intellectual activity as the basic means of sport, according to law of such as human growth and development of skill and function of improving skills, promotes the comprehensive development of improved physical fitness and overall educational level buildup and improve exercise capacity and quality of life and lifestyle of a conscious purposeful organized social activities. Popularity and revitalization of the modern sport only through the widest spread possible dissemination, to some extent, mass media growing concern in society by the media-rich unique content of sports.

In recent years, along with enhancements of the country's economic strength and rich of the people's material and cultural life, a variety of media has been rapid development and the information and dissemination of sports has always been an important part of mass media. As a kind of new social force of contemporary media mess media is more and more coverable to the college students. It can not be ignored that the information of mass media becomes an important channel affect college students' sports life [5].

With the rapid development of high and new technology, the social informationization trend is becoming more and more significant. All kinds of traditional media means and mode of transmission is undergoing tremendous change, the rise of the Internet and other new media provides a new opportunity also poses a bigger challenge for the development of college students and college students' physical education work, contemporary media has become a consolidated development of the important position of college students' physical education work and important environmental factors.

\section{The main influence of mass media sports information on college students' sports life}

The influence of students' sports knowledge. Along with our country sports boom increased year by year, in the propaganda media such as newspapers, magazines, radio "sports field expands unceasingly, the propaganda of the great number of them, the types of reports, is unprecedented. The development of mass media, sports information, make the students can obtain more knowledge 
of sports. For example, some of the "noble sport, golf, the sport was introduced into the relatively late in our country, with the economic life of college students in sport at ordinary times life condition is impossible to come into contact with. Interested in this project, therefore, college students could be obtained by the mass media they want to get information can learn golf game rules, so as to enrich the sports life of college students.

The influence of college students' sports value. More and more students are beginning to realize that different sports will be able to hone the quality of people, still has a healthy personality shaping the positive role of students' extracurricular sports activities on campus has become a beautiful landscape. Their sporting values formation is affected by external factors, especially their own in which the living and learning environment, a variety of modern media are school sports activities to stimulate them to promote their sport from perceptual to rational certain height, and gradually form a proper sporting values. For physical education has an important role in the formation of student sports values. Currently, a large number of post-school enrollment, due to the impact of various factors of space equipment, such as teachers, sports programs can not meet the needs of the students in terms of content, teaching methods and other means, which will sport the student's values and attitudes sports have some negative effects, need to be taken seriously and addressed.."

The impact of students' idol worship. With the rapid development of modern communication devices and media, sports stars using mass media to build and develop the masses have high visibility and reputation of the athlete image more and more.Along with our country competitive sports center of gravity to institutions of higher learning, making scholastic sports stars, can promote the improvement of school sports competition, can be used to attract people, raise funds and promote brands, for the prosperity and development of competitive sports and school spiritual civilization construction service. According to the concerned investigation shows, there is a widespread "idol worship" in the current college students. In the worship of idols, more than 99\% of the "star" is a film and sports, they cheered for their worship of sports stars, even afraid of a long journey, please star idol group photo, signature and collect information about the star's life and hobbies, star endorsements to wear, with star selection of sports equipment, even dressed up like a star shape hairstyle, will be the idol of his feelings poured in, sports stars' influence on college students.

\section{The mass media sports information on college students' sports activities}

Sports information transmission model. The meaning of the information spread is letting receiver to understand the original what they did not know, so the research on the process of spread of information is an important content of information theory, information theory, Shannon the founder of information theory put forward information transmission model in figure.1.

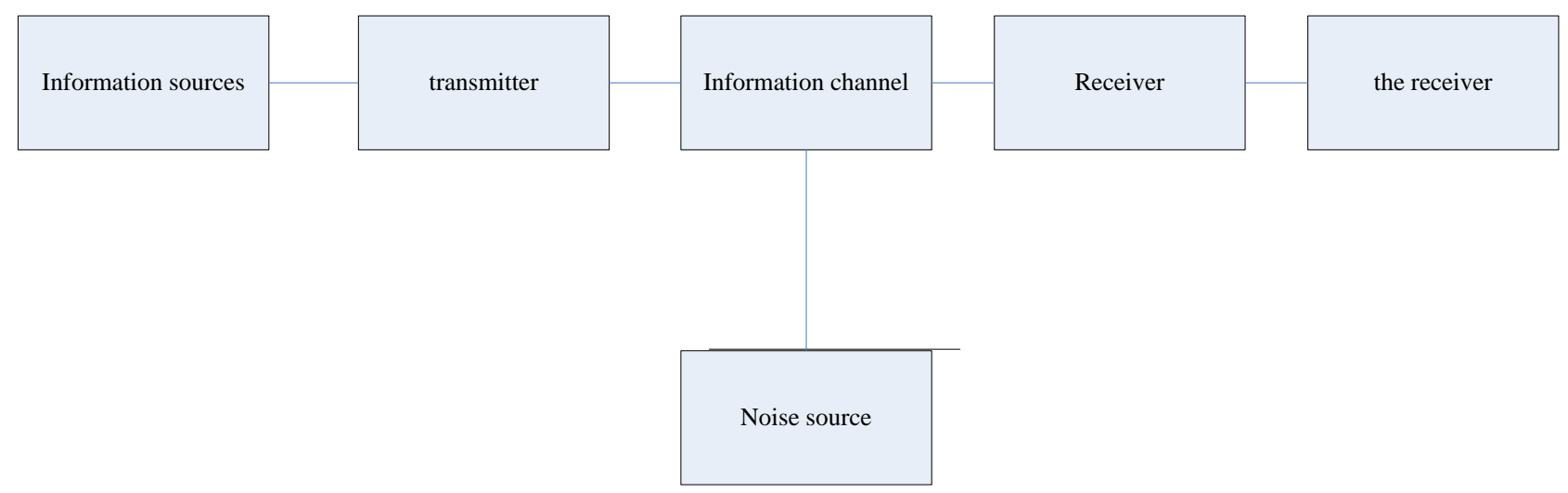

Fig.1 The model of information transmission

This study suggests if the description of mass media of information transmission Will pass to 
carry on the sports information rely on the media (television newspaper radio, computer network, etc.) as a channel You should have a sports information transmission model as shown in Fig. 2.

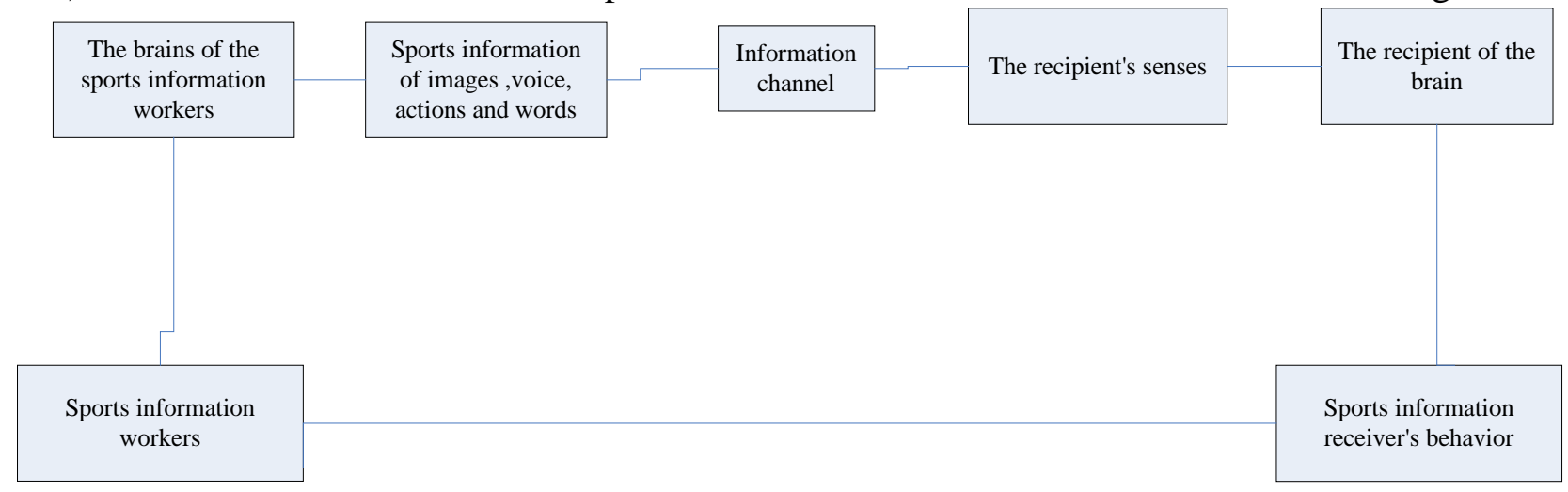

Fig.2 The model of sports information transmission

The demand of sports information in mass media of the college students. First, due to the different requirements of college students' physical and mental development, facing the living environment or the different objective reality, their media need is also different. These media often need to sense of lack of experience, in the form of desire. Second, because the media needs different, their media behavior is different. Through different media contact meet its some kind of psychological needs .of course, there are may lead to not meet other requirements. In short, medium of different students may have different needs, and different medium need may produce different behavior of media contact. We can see the Fig. 3.

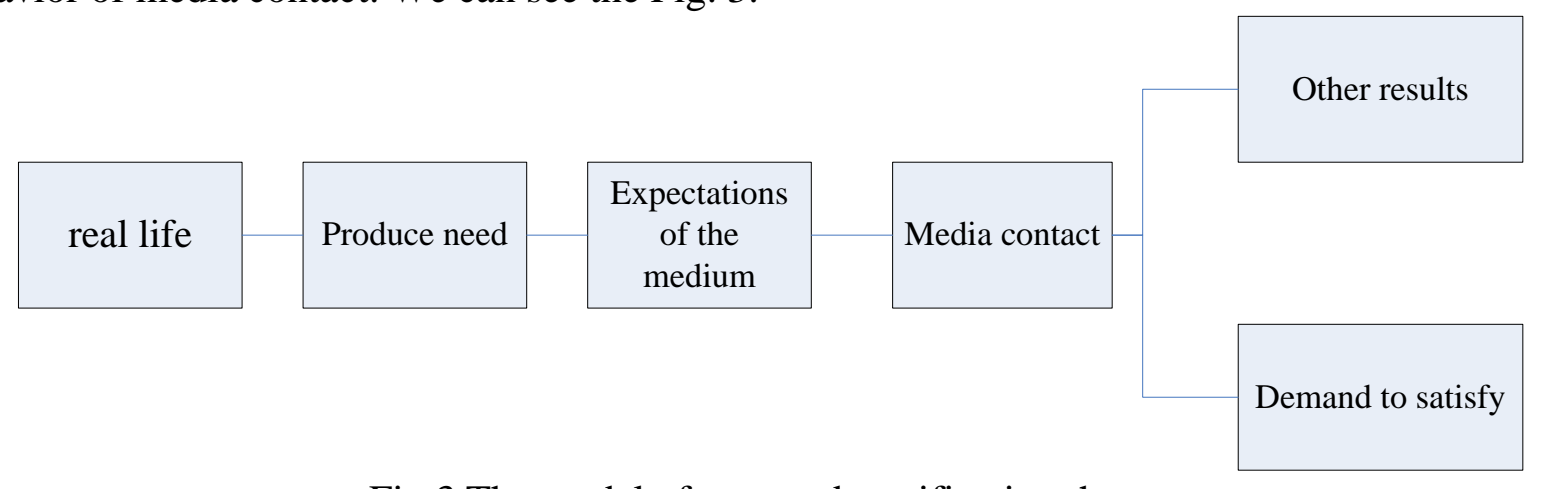

Fig.3 The model of uses and gratification theory

\section{Suggestion on the mass media sports information on college students' sports activities}

For the work of sports media should pay attention to sports professional promotion and propaganda of social cultural taste. Sports propaganda of knowledge should be broad, sports theory should be generous. As a sports publicity media Nature should promote sports entertainment, but should promote sports knowledge. This is the main content of medium sports information. Political, economic, ideological concept, professional ethics, public opinion, mature physical factors such as culture and art to sports penetration impregnation is medium propaganda of the main performance of the social culture grade. Culture grade higher media reports tend to understand more factors of the penetration and depth control the more good work.

Insist on various kinds of sports education, actively explore new era college students sports lifestyle is an effective means of education. College sports should promote healthy lifestyle; we want to increase the intensity of college physical education through the medium of education persists, instilling values of sport. To insist on give them various forms of positive education, in addition to strengthening patriotism, socialism, collectivism, education, college sports and on moral and aesthetic education sports physical education be fine, such as traditional Chinese sports history and China, these educations can establish a correct sporting value for college students. 


\section{Conclusions}

As a whole, due to the spread of the mass media, sports and fitness college life gradually becomes an important part. For information dissemination through transmission the mass media sports knowledge, sports games and entertainment increase understanding of the sport among college students, enhance attention to sports, develop the sports hobbies and interests, and lay a solid foundation for lifelong physical. In order to strengthen the contemporary college sports values and behavior education must be the following from three aspects: First, the sports media workers should pay attention to regulate professional sports publicity. Second, use various forms of sports education, and create a good college sports lifestyle. Finally, positive publicity, "sports star" to the students set a good example for the star.

\section{References}

[1] H.L. Wang, Research on college students' sports information needs and medium price sports interest relations, J. of xi 'an sports institute. 3 (2005) 128-130.

[2] J. H. Flavell, Stage related properties of cognitive development, Cognitive psychology 2 (1971):421-453.

[3] J. J. Jackson, Some consequences of participation's campaign in Victoria .Review of sport leisure. 4 (1979) 89-100.

[4] G.J. Zhang, Mass media influence on adolescent psychology and behavior, Theoretical probe.3 (2006)41-43.

[5] Y.P. Tan, Sunshine sports movement effect on middle school sports teaching research, Yichun University academic. J. 12 (2009). 